\title{
Twinning in polycrystalline aluminium deformed by dynamic channel angular pressing
}

\author{
N. Y. Zolotorevsky ${ }^{1,2, \dagger}$, V. V. Rybin ${ }^{1,2}$, E. A. Ushanova ${ }^{2,3}$, I. G. Brodova $^{4}$, A. N. Petrova ${ }^{4,5}$, \\ N. Yu. Ermakova ${ }^{1,2}$ \\ †zolotorevsky@phmf.spbstu.ru
${ }^{1}$ Institute of Applied Mathematics and Mechanics, Peter the Great Polytechnic University, Polytechnicheskaya Str., 29, St-Petersburg, 195251, Russia
${ }^{2}$ Mechanical Engineering Research Institute of RAS, Belinskogo Str., 85, Nizhnii Novgorod, 603024, Russia
${ }^{3}$ Central Research Institute of Structural Materials “Prometey”, Shpalernaya Str., 49, St-Petersburg, 191015, Russia
${ }^{4}$ M.N. Miheev Institute of Metal Physics, Ural Branch of RAS, S. Kovalevskoy Str., 18, Yekaterinburg, 620990, Russia
${ }^{5}$ Ural Federal University, Mira Str., 19, Yekaterinburg, 620002, Russia

An experimental evidence of deformation twinning in coarse-grained aluminium is presented for the first time using electron backscatter diffraction technique. This phenomenon occurs when using a novel method of severe plastic deformation referred to as dynamic channel angular pressing. A pressing die had two channels of equal cross-sections intersecting at an angle of $90^{\circ}$. A special gun accelerated the sample up to the speed of $100 \mathrm{~m} \mathrm{~s}^{-1}$ and directed it into the die. As a result, the strain rate was about $10^{5} \mathrm{~s}^{-1}$. Twin-oriented mesobands of 3 to $20 \mu \mathrm{m}$ in width appear predominantly near grain boundaries after deformation. Crystallographic characteristics of the mesobands formed in two different grains were examined in detail. Analysis of a deviation of their misorientations from the ideal twin misorientation showed that the first mesoband family could be formed at an early stage of the first pass of the dynamic channel angular pressing, while the second family - at a later stage. The mesobands were suggested to form by successive nucleation and coalescence of microscopic twins during the shear localization. Results have shown that in aluminum, which is characterized by higher stacking fault energy and higher dislocation mobility, deformation twinning occurs only under high strain-rate dynamic deformation.

Keywords: aluminium, high-speed deformation, equal channel angular extrusion, EBSD, twinning.

\section{Introduction}

It is well established that initial grains of polycrystalline materials are subdivided into smaller regions (fragments) under large plastic strains. Fragment's misorientations increase while sizes decrease with increasing strain [1-3]. Based on this phenomenon of fragmentation, different methods of severe plastic deformation have been developed for grain refinement in metallic materials [4]. One of novel methods of severe plastic deformation is the dynamic channel angular pressing (DCAP) [5]. It uses the deformation in a simple shear form similar to the equal channel angular pressing (ECAP) $[6,7]$, but with the strain rate by three to five orders higher. It was shown by transmission electron microscopy (TEM) that a submicron-fragmented structure is formed by DCAP, and the dependence of size parameters of this structure on the number of passes has been investigated for $\mathrm{Cu}, \mathrm{Ti}$ and $\mathrm{Al}$ alloys [8-11]. However, little is known about crystallographic features of the fragmentation and its grain-scale non-uniformity. At the same time, extremely high strain rates used by DCAP give the grounds to expect an inhomogeneous character of microstructure evolution. Indeed, the dynamic character of deformation strengthens the tendency to shear localization [12], and, in particular, it stimulates deformation twinning even in FCC metals with mediate to high stacking fault energy [13-15]. As for twinning in aluminium, nanoscopic twins were observed earlier in some special cases at extreme conditions of high stress [16], e.g., in nanograins [17-19] and at crack tips [20-21]. Recently, it has been shown that a large-scale twinning could be produced in Al single crystals using a method similar to the DCAP: the twins of about $40 \mu \mathrm{m}$ in thickness nucleated from the surface and propagated toward the sample interior [22]. At the same time, until now there has been no observations of deformation twinning in ordinary polycrystalline aluminium. Moreover, little is known about crystallographic features of aluminium fragmentation under DCAP. The purpose of this work was to characterize the microstructure induced by DCAP after a single pressing pass in polycrystalline aluminium using electron backscatter diffraction (EBSD) technique.

\section{Experimental}

A sample of commercial aluminium A7 (99.7\%) was deformed by DCAP (comprehensive description of the 
deformation method one can find in [5] and [9]). The die had two channels of equal cross-section intersecting at an angle of $90^{\circ}$. The sample was $100 \mathrm{~mm}$ in length and $14 \mathrm{~mm}$ in diameter. Special gun accelerated the sample up to the speed of $100 \mathrm{~m} \mathrm{~s}^{-1}$ and directed it into the die. As a result, the strain rate was about $10^{5} \mathrm{~s}^{-1}$. The microstructure of transverse section of the sample was examined, i.e. the pressing direction was perpendicular to the sample surface. EBSD analysis was performed with SEM Quanta 200 3D FEG, an EDAX Pegasus system was used to process the obtained data. The processing of orientation data and the crystallographic analysis were carried out with MTEX software [23].

\section{Results and discussion}

The microstructure of aluminium in the undeformed condition is characterized by a mean grain size of about $1 \mathrm{~mm}$ and wavy grain boundaries. Fig. 1 shows the panoramic orientation map of the aluminium sample after one pass of DCAP. The map has been obtained with the scanning step of $600 \mathrm{~nm}$. Besides the general orientation non-uniformity of the original grains, such as the bands of slightly misoriented subgrains of about $1 \mu \mathrm{m}$ in width and the grain-scale orientation gradients, one can see specific bands with the thickness of 3 to $20 \mu \mathrm{m}$, highly misoriented relative to the matrix. All these bands, being located in different grains, expand from grain boundaries into the grains interiors mostly in vertical direction. Thus, the vertical direction seems to correspond approximately to the intersection line of the principal shear plane with the transverse section of the sample. Thus, the banding may be associated with the shear localization. Most of the bands have more or less developed internal microstructure. Taking this into account, they will be further referred to as mesobands. Two families of mesobands (regions 1 and 2 in Fig. 1) will be considered in detail below.

Fig. 2a, which presents an enlarged image of region 1 , shows that misorientations between the mesobands and the matrix are close to the $\Sigma 3$ twin misorientation (rotation by $60^{\circ}$ along $<111>$ axis) according to the Brandon criterion, that is, the angular deviations $\Delta \theta$ from the ideal twin misorientation are less than $\Delta \theta_{c}=15^{\circ} / \sqrt{3}=8.66^{\circ}$. Correspondingly, a sharp peak near $60^{\circ}$ is seen on the histogram of misorientation angles obtained for this region (Fig. 2b). The angular deviations $\Delta \theta$ were also determined locally along some boundaries of the mesobands. These measurements were carried out at successive boundary points within the segments of boundaries (see Fig. 2a), where starting and end points are indicated by arrows on the orientation map. The results are presented in Fig. $2 \mathrm{c}$ as a function of coordinate defined as the distance along the straight line connecting the indicated points. One can see that the deviation $\Delta \theta$ varies along these boundaries from $2^{\circ}$ to $10^{\circ}$. Its average value is about $4^{\circ}$ for segment 1 , while it is somewhat higher for segments 2 and 3 . Noteworthy, the morphology of these twins is similar to that of the deformation twins discovered in $\mathrm{Al}$ single crystals by Zhao et al. [22]. Small deviations from the ideal twin rotation, also similar to those observed in [22], may be induced by plastic deformation proceeded after the twin appearance [24-26].
Recently, it has been shown on an example of compressed austenitic steel that mean values of the angular deviation $\Delta \theta$ on the boundaries of annealing twins are $10^{\circ}$ and $15^{\circ}$ for the strains of 0.36 and 0.7 , respectively [26]. Considering these data, the estimated strain accumulated after the twinning event is about $0.1 \ldots 0.2$. At that, increased deviation level observed for the segments 2 and 3 may indicate a larger local strain in those parts of the region.

Therefore, the twins of this family might nucleate at a later stage of deformation during the first DCAP pass. Note, however, that the analysis based on the misorientation data obtained in [26] for the case of compression may underestimate the post-twinning strain. Actually, in the presence of deformation twinning a primary slip plane must coincide with the plane of coherent twin boundary, and, hence, primary dislocations will not induce additional misorientation at this boundary. In such a case, the straininduced change of misorientation at the twin boundaries must be relatively small.

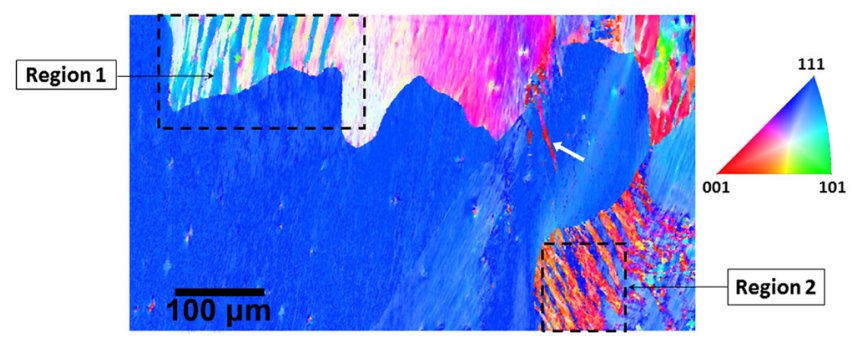

Fig. 1. (Color online) Inverse pole map of the pressing direction of aluminium sample after one DCAP pass.

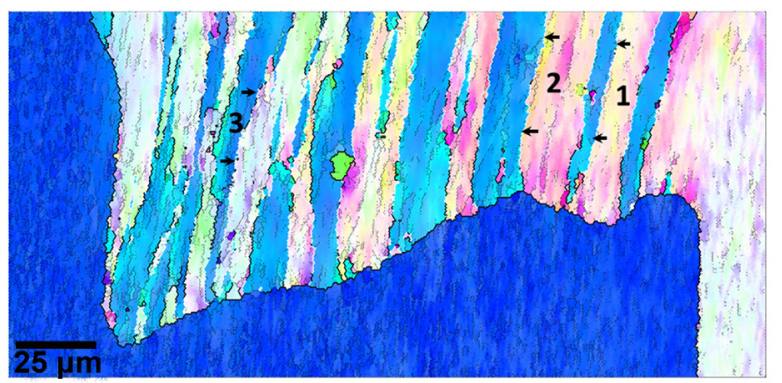

a

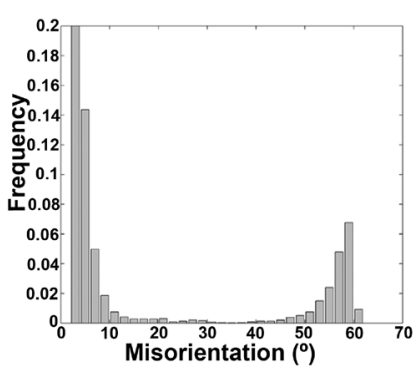

b

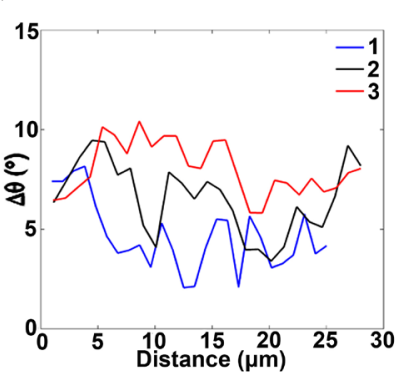

$c$
Fig. 2. (Color online) EBSD analysis of region 1. Inverse pole map of the pressing direction superimposed with the boundary map (a). Black thin lines: $2^{\circ}<\theta<15^{\circ}$; black thick lines: $\theta>15^{\circ}$; white lines: twin boundaries according to Brandon criterion. The arrows indicate points between which angular deviations $\Delta \theta$ were determined top-bottom along the boundaries. Misorientation angle distribution (b), angular deviations $\Delta \theta$ from the ideal twin misorientation versus distance along the segments of boundaries marked on the orientation map by numbers 1,2, 3 (c). 
The mesobands belonging to the second family (region 2 in Fig. 1) differ from the bands considered above: they are more fragmented inside, and their external boundaries are more ragged. To examine the internal structure of these mesobands in more detail, the area marked as region 2 was mapped using the reduced scanning step of $200 \mathrm{~nm}$ (Fig. 3). One can see in Fig. 3a that the level of misorientations inside mesobands is considerably higher than in the matrix. In addition to multiple low-angle boundaries extended along the mesobands, transverse boundaries occur. The steps formed in the points, where the latter cross the external boundaries of mesobands, provide evidence that a certain localized shear is associated with them. Additional information on their structure gives an image quality (IQ) map (Fig. 3b). A map of this kind is known to visualize boundaries between small crystallites, though corresponding orientation map would not necessarily reveal them [27]. Actually, Fig. 3b shows that the mesobands have apparent lamellar constitution. As the average lamella width is close to the scanning step, one cannot exclude an opportunity of existence of even thinner lamellae among them.

Compared to region 1 , misorientations between the mesobands and the matrix in region 2 show larger deviation from the original twin misorientation, and very small portion of the boundaries appears to satisfy the Brandon criterion (Fig. 3a). This fact manifests itself also in a broadening of the high-angle peak in the misorientation distribution (Fig. 3c) as well as in the results of local misorientation analysis (Fig. 3d). The average angular deviation obtained is $\sim 16^{\circ}$. According to the results of [26] (see above), such a deviation can be expected after strain a little larger than 0.7 .

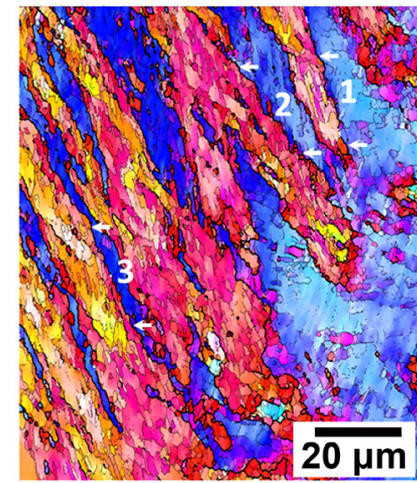

a

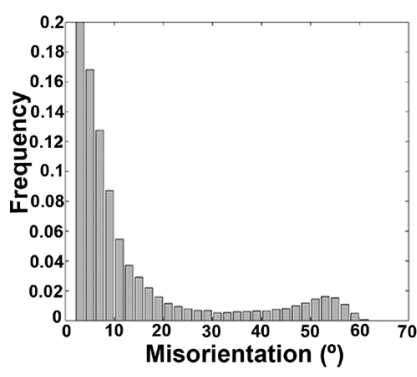

C

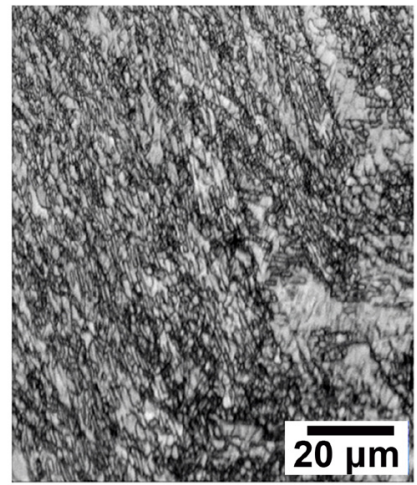

$\mathrm{b}$

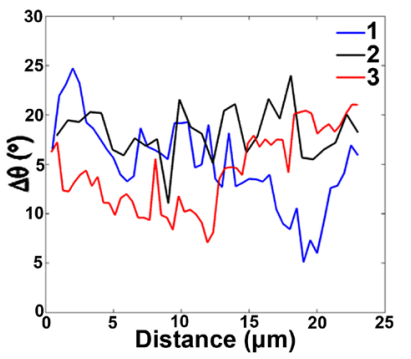

d
Fig. 3. (Color online) EBSD analysis of region 2. Inverse pole figure map of the pressing direction superimposed with boundary map (a). The arrows indicate points between which angular deviations $\Delta \theta$ were determined top-bottom along the boundaries. IQ map (b), misorientation angle histogram (c) and angular deviations $\Delta \theta$ from the twin misorientation versus distance along the segment of boundaries marked on the orientation map by numbers 1, 2, 3 (d).
Therefore, our analysis suggests that we deal with twins in both regions examined, but they formed at different stages of the deformation. Evidently, the occurrence of deformation twinning depends on the grain orientation. If the initial orientation is favorable for twinning, the twins may nucleate early during deformation. In other grains, the twinning may occur only at a later stage, if they attain a favorable orientation as a result of deformation-induced lattice rotation.

It is worth noting that some other band-like formations with high-angle misorientations relative to the matrix occur on the panoramic map in Fig. 1, e.g., wedge-shaped region located upward from the region 2 and indicated by the arrow. Misorientation of the latter deviates so strongly (by more than $20^{\circ}$ on the average) from the twin one, that it is hardly worth to discuss its twin origin based on the crystallographic data only. Nevertheless, one cannot exclude this possibility with regard to the above consideration.

Notice that earlier deformation twins in FCC metals were observed mostly in the form of very thin (less than $100 \mathrm{~nm}$ in thickness) lamellae. By contrast, the twins described in the present study as well as the "macrodeformation twins" observed by Zhao et al. in Al single crystals [22] were up to tens of micrometers in thickness. To understand this controversy, a study of Miyamoto et al. [28] may be of interest. They observed mesoscopic (5 to $10 \mu \mathrm{m}$ in thickness) twin-oriented shear bands in copper single crystals deformed by ECAP. On IQ map, those bands have lamellar internal structure, which closely resembles the structure revealed in Fig. 3b. Along with such thick twin-oriented bands, individual twin lamellae were observed in the matrix by TEM in [28]. It is the author's opinion that thick bands were formed by a coalescence of such microtwins, inheriting their orientation [28]. The structural similarity mentioned above allows one to suggest a similar mechanism of the mesoband formation in aluminium. Though, it realizes at extremely high strain rates only. After nucleation of a first twin at a grain boundary, next ones may nucleate more easily due to the effect of autocatalysis. Then, a mesoband forms as a mesoscopic shear instability by a formation and coalescence of multiple microtwins.

\section{Conclusions}

In summary, deformation twinning was shown to develop by a formation of mesobands in coarse-grained aluminium under the DCAP. This process occurs in the grains, which have orientations favorable for twinning. Based on the crystallographic analysis, it was concluded that the twins could nucleate both at an early stage and at a later stage during the DCAP pass, depending on the initial orientation of the grain and its rotation trajectory. The mesobands are suggested to form by successive nucleation and coalescence of microscopic twins during the shear localization.

In contrast with twinning in copper, observed during quasi-static deformation by ECAP [28], in aluminum, which is characterized by higher stacking fault energy and higher dislocation mobility, deformation twining can occur only under high strain-rate dynamic deformation (DCAP). 
Acknowledgments. The authors appreciate financial support of the Russian Science Foundation, project No. 15-13-20030. The DCAP of the samples was performed according to the Russian government FANO task "Structure", No. 0120146333.

\section{References}

1. V.V. Rybin. Large plastic deformation and ductile failure of metals. Metallurgiya, Moscow. (1986) 224 p. (in Russian). [В.В. Рыбин. Большие пластические деформации и разрушение металлов. Металлургия, Москва. (1986) 224 с.]

2. D. A. Hughes, N. Hansen. Acta Mater. 45, 3871 (1997).

3. F.J. Humphreys, M. Hatherly. Recrystallization and related annealing phenomena. Elsevier. (2004) 605 p.

4. T.G. Langdon. Acta Mater. 61, 7035 (2013). DOI: 10.1016/j.actamat.2013.08.018

5. I.G. Brodova, I.G. Shirinkina, O.A. Antonova, E. V. Shorokhov, I. I. Zhgilev. Mater. Sci. Eng. A503, 103 (2009). DOI: 10.1016/j.msea.2007.12.060

6. V.M. Segal, V.I. Reznikov, A.E. Drobyshevskii, V.I. Kopylov. Russ. Met. 1, 99 (1981) (in Russian). [В.М. Сегал, В.И. Резников, А.Е. Дробышевский, В.И. Копылов. Пластическая обработка металлов простым сдвигом. Известия АН СССР. Металлы. 1, 115 (1981)].

7. R. Z. Valiev, T. G. Langdon. Progress in Mater. Sci. 51, 881 (2006).

8. I. G. Brodova, E.V. Shorokhov, I.G. Shirinkina, I.N. Zhgilev, T.I. Yablonskikh, V.V. Astaf'ev, O. V. Antonova. Physics of Metals and Metallography. 105 (6), 594 (2008). DOI: 10.1134/S0031918X08060100

9. V.I. Zel'dovich, E.V. Shorokhov, N.Yu. Frolova, I.N. Zhgilev, A.E. Kheifets, I. V. Khomskaya, V.M. Gundyrev. Physics of Metals and Metallography. 105 (4), 402 (2008). DOI: 10.1134/S0031918X08040145

10. I. V. Khomskaya, V.I. Zel'dovich, E.V. Shorokhov, N. Yu. Frolova, I. N. Zhgilev, A.E. Kheifets. Physics of Metals and Metallography. 105 (6), 586 (2008). DOI: 10.1134/S0031918X08060094

11. I.G. Brodova, E.V. Shorokhov, A.N. Petrova, I. G. Shirinkina, I. V. Minaev, I. N. Zhgilev, A. V. Abramov. Rev. Adv. Mater. Sci. 25, 128 (2010).
12. Y. Xu, J. Zhang, Y. Bai, M. A. Meyers. Metal.Mater.Trans. 39A, 811 (2008). DOI: 10.1007/s11661-007-9431-Z

13. O. Johari, G. Thomas. Acta Metall. 12, 1153 (1964).

14. V.V. Rybin, N.Yu. Zolotorevsky, E. A. Ushanova, Technical Physics. 59 (12), 1819 (2014). DOI: 10.1134/ S106378421412024X

15. V. V. Rybin, N. Yu. Zolotorevsky, E. A. Ushanova. Physics of Metals and Metallography. 116 (7), 730 (2015). DOI: 10.1134/S0031918X1507011X

16. I. J.Beyerlein, X.Zhang, A.Misra.Annu. Rev.Mater. Res.44, 329(2014).DOI: 10.1146/annurev-matsci-070813-113304

17. M. Chen, E. Ma, K. J. Hemker, H. Sheng, Y. M. Wang, X. Cheng. Science. 300 (5623), 1275 (2003). DOI: $10.1126 /$ science. 1083727

18. X. Z. Liao, F. Zhou, E. J. Lavernia, D. W. He, Y. T. Zhu. Appl. Phys. Lett. 83, 5062 (2003). DOI: 10.1063/1.1633975

19. M. Yu. Gutkin, I. A. Ovid'ko and N. V.Skiba. Phys. Rev. B74, 172107 (2006). DOI: 10.1103/PhysRevB.74.172107

20. R. C. Pond, L. M. F. Garcia-Garcia. Inst. Phys. Conf. Ser. 61, 495 (1981).

21. S. Hai, E. B. Tadmor. Acta Mater. 51, 117 (2003). DOI: 10.1016/S1359-6454(02)00367-1

22. F. Zhao, L. Wang, D. Fan, B.X. Bie, X. M. Zhou, T. Suo, Y.L. Li, M.W. Chen, C.L. Liu, M.L. Qi, M.H. Zhu, S.N. Luo. Phys. Rev. Lett. 116, 075501 (2016). DOI: 10.1103/PhysRevLett.116.075501

23. F. Bachmann, R. Hielscher, H. Schaeben. Solid State Phenom. 160, 63 (2010). DOI: 10.4028/www.scientific. net/SSP.160.63

24. P. Cizek, A. Whiteman, M. Rainforth. Journal of Microscopy. 213 (3), 285 (2004). DOI: 10.1111/j.00222720.2004.01305.x

25. D. Jorge-Badiolga, A. Iza-Mendia, I. Gutierrez. Journal of Microscopy. 235 (1), 36 (2009).

26. N. Yu. Zolotorevsky, N.Yu. Ermakova, V.S. Sizova, E. A. Ushanova, V. V. Rybin. J. Mater. Sci. 52, 4172 (2017). DOI: $10.1007 /$ s10853-016-0510-7

27. H. Alimadadi, A. Bastos, K. Pantleon. Proceeding of 33rd Risø International Symposium on Materials Science. 33, 175 (2012).

28. H. Miyamoto, A. Vinogradov, S. Hashimoto, R. Yoda. Mat. Trans. 50, 1924 (2009). DOI: 10.2320/ matertrans.M2009054 